\title{
LA PRAGMATIZACIÓN DEL CONOCIMIENTO EN LA UNIVERSIDAD "MODERNIZADA". OTROS SIGNIFICADOS Y ACCIONES EN FRAGMENTOS DE NUESTRA MEMORIA COLECTIVA
}

Prof. María Josefina Carnevale (Universidad Nacional de Rosario)

\section{Resumen}

Este trabajo focaliza su mirada en la crisis de la Universidad Argentina en el marco del proceso de transformación que fue imponiendo la economía capitalista, a partir de las últimas décadas del siglo XX, hasta nuestros dias.

La "modernización" impuesta a la Universidad desde los parámetros de la eficiencia, provocaron actos de resistencia por parte de la comunidad educativa. A través de la selección de tres "acontecimientos" institucionales considerados relevantes se pretende reconstruir un fragmento de la memoria colectiva de la Facultad de Humanidades y Artes de la U.N.R., principalmente. Estos "actos del recuerdo" provocan una dinámica al servicio de las acciones presentes, para no renunciar a un deseo emancipatorio. Desde ese lugar se consideran valiosas las ponencias de los distintos docentes, que junto con los autores seleccionados pretenden generar un debate para dar respuestas a la crisis socio-económica e institucional de estos "nuevos tiempos".

Ante la nueva ideologia que impone un "lenguaje unidimensional" se pone en escena la dimensión histórica del significado/s de los actores en este proceso que permanentemente sostiene la relación dialéctica entre educación-sociedad.

Las demandas "pragmáticas" de adaptación al mundo laboral requieren que la Universidad tenga una mirada crítica cuando se propongan cambios curriculares.

Palabras clave

Crisis, resistencia, modernización, memoria colectiva, significados.

$$
-27-
$$




\section{Summary}

This paper focuses on the crisis of the University in Argentina in the context of the process of transformation that the capitalist economy has been imposing from the last decades of the $20^{\text {th }}$ century until today.

The "modernization" imposed on the University to fulfil parameters of efficiency has caused acts of resistance on the part of the education community. Through the selection of three institutional "events" considered relevant, it is intended mainly to reconstruct a fragment of the collective memory of the Facultad de Humanidades y Artes of the U.N.R. These "acts of memory" create dynamics that respond to present actions, so as not to relinquish a desire for emancipation. From that perspective, the speeches of various professors who, along with the selected authors, intend to generate a debate that gives answers to the socio-economical and institutional crisis of these "new times", are deemed valuable.

Against the new ideology that imposes a "one-dimensional language" the historic dimension of the meaning/s of the actors in this process that constantly maintains the dialectic relationship education-society is presented. The "pragmatic" demand for adaptation to the world of employment requires the University to have a critical view when changes in the curriculum are proposed.

\section{Key words}

Crisis, resistance, modernization, collective memory, meanings.

\section{Introducción}

Tener la oportunidad de escribir para el segundo número de la Revista de nuestra Escuela me provoca placer y al mismo tiempo movilización ya que es un espacio de libertad que tenemos para expresar nuestras ideas y prácticas. Es un compromiso ético con nosotros mismos y con los otros el animarnos a dialogar con los textos y personalmente acerca de lo que pensamos. En ese sentido la Revista se convirtió en una instancia de encuentro, que era uno de los objetivos.

Es posible también que nuestra publicación haya generado otra inserción de la Escuela y de cada uno de nosotros en la Institución. Probablemente ese es el nexo, no casual, que me ha permitido rescatar de mi archivo un documento que siempre guardé como valioso y hoy considero importante volver a analizarlo porque forma parte de nuestra historia institucional. Es en ese entramado de la reconstrucción post-dictadura cuando se creó nuestra carrera de Ciencias de la Educación (1985) y desde alli fuimos construyendo este nuevo espacio del saber conjuntamente con nuestra identidad docente.

Me estoy refiriendo al Documento: "El país, la universidad y la crisis", (1989) (1) escrito por docentes y algunos alumnos de la Facultad de Humanidades y Artes. U.N.R. para pensar y analizar ese momento histórico por sus implicancias para la Universidad Argentina y nuestra Facultad en particular. Los propósitos de la convocatoria y la publicación fueron: "la profunda crisis que afecta al país y a la Universidad, que exige a todos los miembros de la comunidad universitaria a tomar posición para definir los futuros pasos en defensa de la institución."

En las distintas ponencias se tiende a clarificar qué Universidad necesitamos y para qué la necesitamos. Hay coincidencias en las posturas al plantear que una misión ineludible de la Universidad es abrir interrogantes. Algunos de esos docentes hoy ya no están: Insúa, Elda, Rubén Naranjo y Nicolás Rosa, pero forman parte de la memoria de nuestra Facultad como sujetos críticos y comprometidos con la tarea.

\section{¿Qué cuestiones me interpelaron?}

El retorno de la democracia a los claustros universitarios en general y al ámbito de nuestra Facultad en particular significó asumir una verdadera tarea de reconstrucción.

A los cinco años de ese proceso de reconstrucción los docentes se sienten obligados a hacer un balance crítico de sus logros y errores a fin de reflexionar conjuntamente sobre ellos y procurar su superación.

Ese balance debe insertarse necesariamente en el interior de una realidad social que plantea límites al desarrollo de una práctica democrática, como el presupuesto educativo insuficiente, bloqueando la labor de docencia e investigación.

El ataque a la Universidad no es como en la época de la dictadura militar: con represión y anticientificismo, sino que se expresa en una actitud más elaborada de trasladarle a la Universidad desde el Estado, los instrumentos para que ella misma contribuya a su transformación. Es plantearle que ella misma se "modernice" y que sean los mismos universitarios los que se encarguen de destruirla.

El ataque ahora es que la Univ. ha bajado su nivel académico, que es inoperante, que debe autofinanciarse, que debe aprender de la privadas. Financiamiento-Arancelamiento-Restricción al ingreso es un tándem de politicas acordes con la revolución productiva propuesta por Menen. 
Retomar estas cuestiones nos posibilitan reconstruir la/s memoria/s de nuestra institución en el entrecruzamiento de las distintas miradas: desde lo micro y lo macro, desde la relación educación-sociedad y en ese mirar para analizar la complejidad, asumir la propuesta de realizar una reflexión critica. Práctica casi en extinción, extinción que está sustentada en la vertiginosidad de los cambios de estos tiempos posmodernos, donde no hay tiempo para reflexionar, sólo para recibir información. Aunque el problema debería estar centrado no en el acto de reflexionar en si, sino en el valor y alcance de la reflexión como motor de fundamentación y cambio cualitativo de nuestras prácticas. Nos posibilitaria constituirnos en sujetos críticos- transformadores de la realidad si realizáramos una autocrítica y una crítica contextualizada; es decir, teniendo en cuenta el proceso histórico de la Universidad, en el marco de las transformaciones politicas, económicas, sociales en nuestro país y en el mundo. Proceso/s que nuestros alumnos de Ciencias de la Educación no deben desconocer. Esta acción material y simbólica de sacar a la luz la propia luminosidad del texto la relaciono con la expresión: "actos del recuerdo" que siempre están al servicio de las acciones presentes. Se recuerdan para que se pueda sentir, evocar, imaginar, desear o sentirse impelido a hacer algo, aquí y ahora, o en un futuro más o menos próximo. Lo importante es lo que queremos hacer, o que queremos que se haga, y lo menos importante es que el recuerdo sea exacto. Lo que nos importa es que el recuerdo sirva para los propósitos de la acción presente. Por eso la memoria colectiva está hecha también de olvidos, de olvido de lo que no resulta memorable, por irrelevante, por doloroso, por incómodo. Así respecto a lo sucedido en un mismo tiempo unos grupos recuerdan y (olvidan) algunas cosas y otros hacen eso mismo pero con cosas muy diferentes. Por eso hay disputas por la memoria e incluso combates por el control de la memoria colectiva. Esa dinámica de recuerdos - olvidos hace que la memoria (la personal y la colectiva) sea siempre dinámica... ( ). Carretero M. y otros, (2006) (2).

\section{¿Cuál es la crisis que plantea la urgencia de la movilización y re-} dacción de ese documento?

Se refiere a la transformación, modernización, de la Universidad que se ha puesto en marcha, para convertirla en un eslabón dependiente del sistema de producción capitalista formando profesionales idóneos adaptados a las reglas del capitalismo internacional. Es en ese clima de transformaciones en el plano internacional con sus repercusiones en lo nacional que la educación superior es objeto de reflexiones, desde distintas miradas. Particularmente en Argentina la tradición que valora la Universi- dad pública se resiste a adaptarse a las nuevas políticas públicas cuyos ejes son: las privatizaciones y la capacitación para el mercado.

La preocupación también se manifiesta por la urgencia a cambiar los planes de estudio, la incorporación de nuevos contenidos, ante los requerimientos de la "modernización". Se pone de manifiesto en la realización del $1^{\circ}$ Simposio Internacional, organizado por la Facultad de Ciencias de la Educación de la U.N.E.R. en 1992, acerca de "Las perspectivas del Curriculum universitario ante el siglo XXI". (3)

En la ponencia del Profesor Follari, R. (1994) (4) se trata la nueva problemática que comienza a atravesar a la Universidad Argentina: la evaluación. Analiza la tensión que produce porque la universidad va a ser evaluada por las pautas que impone el reordenamiento mundial. A nivel presupuestario, el porcentaje dedicado a educación será una decisión que deben tomar los gobiernos de turno con la supervisión de los organismos internacionales, y a nivel de la evaluación de la calidad educativa se hará desde los parámetros de la eficiencia. Por otro lado, el autor plantea porqué no aceptamos el desafio del cambio poniéndonos a pensar qué universidad necesitamos y qué tenemos que modificar. Considera que hay una unificación discursiva pragmatizante porque no basta con afirmar que la realidad ha cambiado en un sentido dado para aceptar plegarse a ella. No se discute la dirección de esos cambios y la Universidad parece someterse ciegamente a ella como si se tratara de una fatalidad o un destino. La tendencia a la evaluación no sólo es propia de los países dependientes sino que representa un rasgo común a todo el capitalismo actual, pero en Argentina resulta inevitable asociar la evaluación al racionamiento de los recursos para las universidades. No sólo se trata de incrementar el rendimiento de estas instituciones en base a criterios de racionalidad instrumental, sino también de controlar modos de utilización de recursos con ciertos fines. Se sabe que la evaluación no es neutra porque es primariamente una cuestión teórica ya que son los criterios conceptuales los que demarcan el campo empírico. Las universidades se encuentran así en una encrucijada de legitimidad, no sólo están cuestionadas por los gobiernos sino que también han perdido parte importante de su prestigio público tanto por la caida de los fundamentos que es propia de lo posmoderno como por la decadencia de las funciones propiamente académicas. Aunque al mismo tiempo considera que si las universidades no cambian, "mueren", pero se puede caminar en una dirección critica ya que hay mucho para corregir y mejorar. Plantea el cambio en un sentido diferente al cambio pragmatista de los organismos gubernamentales e internacionales.

En su obra Marcuse, H. (1968) ya nos habia anticipado que lo que 
está en juego es la difusión de una nueva ideología que se propone describir lo que pasa al eliminar los conceptos capaces de entender lo que pasa. Expresa que existe una diferencia irreductible entre el universo del pensamiento y el lenguaje cotidiano por un lado y el pensamiento y el lenguaje filosófico por el otro. Esa aceptación radical de lo empírico viola lo empirico porque habla el individuo abstracto, mutilado, que experimenta y expresa sólo aquello que le es dado, cuya conducta es unidimensional y manipulada. El mundo experimentado es el resultado de una experiencia restringida, de esa forma el mundo empírico llega a ser el objeto del pensamiento positivo. La transformación del pensamiento crítico en positivo ocurre en el tratamiento de los conceptos universales que se transforman en términos operacionales y de conducta. El universo establecido del razonamiento está atravesado por la marca de las formas especificas de dominación, organización y manipulación a las que están sujetos los miembros de la sociedad. El lenguaje multidimensional es convertido en lenguaje unidimensional, los significados diferentes y conflictivos ya no se interpenetran sino que son mantenidos aparte, la explosiva dimensión histórica del significado es silenciada.

Por eso considero que fue tan valiosa la convocatoria y el documento redactado al que me referi anteriormente porque hubo la necesaria apertura como para ver los cambios que se estaban produciendo y querer dar respuesta a ellos. Los cambios modernizantes en la educación argentina se concretan en las nuevas legislaciones, me estoy refiriendo a la Ley Federal de Educación $N^{\circ} 24195 / 93$ y especificamente a la Ley de Educación Superior $N^{\circ} 24521 / 95$, que fijan un nuevo marco regulatorio. La educación como valor económico es abordada desde los conceptos de gasto y eficiencia; evaluación-acreditación se convierten en un eje fundamental, en un dispositivo tendiente a la regulación del sistema. Se van obturando los debates y a veces la resistencia al cambio es la única arma con que se cuenta para evitar los avasallamientos a una tradición.

En el mismo Simposio de la U.N.E.R. Torres, C. (1994) (5) expone acerca de "La Educación Superior en América Latina: de la Reforma de 1918 al ajuste estructural de los noventa" ofreciendo un panorama de los diferentes proyectos puestos en juego en la política universitaria hasta la configuración de la Universidad de masas y el impacto del ajuste estructural de los noventa. Cuando se refiere a la Universidad de la Posmodernidad y del ajuste estructural explicita que durante los años setenta y ochenta se produce un nuevo proceso de reorganización de la división internacional del trabajo y del capital. La hegemonía americana ha declinado, incluso luego de haber llevado la Unión Soviética a la bancarrota financiera con la carre-

$$
-32-
$$

ra armamentista. Japón y Alemania emergen como poderosos competidores económicos de la posguerra. El intercambio internacional ha tomado dimensiones sin precedentes, particularmente con el anuncio de la unificación europea y el mercado común entre Canadá, Méjico y los EE.UU. en 1992. La integración de las economias internacionales alcanza niveles sorprendentes. La experiencia altamente exitosa de los Nuevos paises industrializados como Corea, Taiwán, Hong Kong, Singapur, basados en producción de bajo costo, constituyen un modelo para los recién llegados al sistema internacional. La adopción de estrategias globales de producción por las compañías multinacionales crea un mundo económica y políticamente más interdependiente, con fuertes presiones para recortar el valor de la fuerza de trabajo y el reemplazo de las fórmulas económicas Keynesianas. En América Latina la deuda externa y las limitaciones de acumulación doméstica de capital llevaron a las nuevas democracias a adoptar los dictados de la política económica del Fondo Monetario Internacional con sus condicionamientos, entre ellos condicionamientos en la política educativa de la región. Hay nuevos esfuerzos por transferir el costo de los servicios a los usuarios, incrementar la participación del sector privado en educación, reorientar la inversiones educativas hacia las áreas que los estudios del Banco Mundial han considerado que ofrecen las mejores tasas de retorno, es decir la educación primaria y educación básica. Reducir el costo de la educación afectando el nivel de los salarios y promover la descentralización de los servicios educativos como una medida para redefinir las relaciones de poder y educativas entre los gobiernos nacionales, provinciales y municipales.

Asistimos a ese evento con compañeras de la cátedra y lo recordamos como muy movilizante por las exposiciones tan claras y explícitas acerca de lo que estaba aconteciendo en el plano nacional e internacional. Las relaciones entre educación y sociedad se plantearon como eje principal para poder pensar un nuevo curriculum, eje de análisis fundamental para realizar propuestas de cambio curricular.

Otro autor al que me interesa remitirme es Stuart Hall (1993) (6), porque se plantea la siguiente pregunta: ¿Qué decimos cuando hablamos de "nuevos tiempos"? ¿Cómo podemos describir sus tendencias contradictorias? En los debates habituales se trata de describir las distintas dimensiones de este cambio con una variedad de términos: post industrial, post fordismo, revolución del sujeto, post modernismo; ninguno es totalmente satisfactorio. Todos expresan algo que ha sido dejado atrás con respecto al lugar a donde nos dirigimos, y cada uno significa algo importante en el debate sobre los "nuevos tiempos". El autor considera que el término "post 
fordismo" es más amplio que post industrial, porque sugiere una época diferente respecto a la era de la producción masiva caracterizada por los productos estandarizados, la concentración del capital y las formas de organización y disciplina del trabajo propias de "taylorismo". Considera que hay una gran mayoria de comentaristas que acuerdan que el término post fordismo cubre algunas de las siguientes características del cambio:

Una tendencia hacia las nuevas tecnologias de la información a partir de las tecnologías electrónicas o quimicas que llevaron a una segunda revolución industrial en este siglo y señalaron el avance de las economias de Estados Unidos, Alemania o Japón a una posición líder y un relativo retroceso de la economía británica.

Una tendencia hacia formas más flexibles, especializadas y descentralizadas del proceso de trabajo. Crecimiento del este y sus regiones a partir de industrias de alta tecnología basada en la computación.

La desregulación de las funciones y los servicios provistos sobre bases corporativas

Transformaciones en el rol decisivo del consumo que se verifican, con un énfasis mayor en la elección y la diferenciación de productos, en la comercialización, presentación y diseño, en la "pesca" de consumidores por estilo de vida, gusto y cultura y no por el registro general de categorías de clase.

Un retroceso en la producción de clase trabajadora especializada masculina, el crecimiento correspondiente de las clases de servicio y empleados medios. En el dominio del trabajo pago hay un trabajo "part time" o más flexible asociado con la "feminización" o "etnización" de la fuerza de trabajo.

Una economía dominada por las multinacionales, con su nueva división internacional del trabajo y su mayor autonomia del control de los estados nación.

La globalización de los mercados financieros

La emergencia de nuevos patrones de división social, especialmente entre los sectores "privados" o "públicos" y entre los dos tercios que tienen expectativas de crecimiento con respecto a los "nuevos pobres" del otro tercio que es dejado atrás en cualquier dimensión de las oportunidades sociales.

Plantea el autor que algunos críticos han sugerido que "post fordismo" es un concepto que indica el retorno al viejo y desacreditado modelo de base y superestructura que conduciría a un determinismo económico, sin embargo la metáfora "post fordismo" no tiene necesariamente esa implica- ción. De hecho, está modelada sobre el uso inicial que Gramsci hace del término "fordismo" para connotar una tendencia de la civilización capitalista que por supuesto no se reducía a un mero fenómeno de base económica. "Post fordismo", por su parte, señala el rol constitutivo en el cual las relaciones sociales y culturales permiten analizar el sistema económico. Este término a pesar de referirse a la estructura y la organización económica tiene una significación social y cultural más amplia. Así el requisito para tratar de pensar las complejidades y ambigüedades de los nuevos tiempos es simplemente abrir nuestras mentes al carácter profundamente cultural de esta revolución. Si el "post fordismo" existe, es tanto una descripción cultural como un cambio económico. En efecto, la distinción es casi inútil. La cultura ha dejado de ser, si alguna vez lo fue, una agenda decorativa al mundo "pesado" de la producción, la palabra es ahora tan material como el mundo. A través del diseño y las tecnologias, la estética ha penetrado al mundo de la producción moderna. La cultura moderna es sin duda, material en sus prácticas y modos de producción y el mundo material de las mercancías y tecnologías es profundamente cultural... ( ) Al finalizar se pregunta: ¿Podría haber nuevos tiempos sin nuevos sujetos?...

Otro acontecimiento al que me voy a referir fue la convocatoria a fines de 1999 que realizó la Escuela de Posgrado de nuestra Facultad, (evento coorganizado con la Escuela de Comunicación Social), para tratar la constitución de la enseñanza de posgrado en el campo de las Ciencias Sociales. Participaron un centenar de especialistas nacionales y extranjeros de ese campo específico, convirtiéndose en una reunión científica que superó los objetivos planteados y las expectativas, donde la polémica y el disenso, fueron el motor de las discusiones. Los pensamientos de los diferentes autores fueron sintetizados en el texto "Ciencias Sociales y Posgrado", que considero muy importante para nuestra memoria académica, en la construcción de un campo del saber. Se exponen ideas diferentes con categorias constitutivas del campo de las Ciencias Sociales en el contexto de las transformaciones nacionales e internacionales, generándose preguntas, afirmaciones, dudas. Podríamos decir especialistas que asumieron el rol de intelectuales poniendo sobre la mesa elementos teóricos para ser discutidos y puestos en tensión con el contexto. Tomo en consideración algunas ideas alli expuestas:

"Lo que se está constituyendo es en definitiva una actualización y una funcionalización de un nuevo profesional tecnólogo para un mercado que va a decidir más allá de lo que en occidente o en la modernidad fue 10 esencial: discutir el mundo de ideas para expresar realmente si la historia tiene, tuvo o tendrá un sentido"... ( ). Casullo, N. (2001) (7). 
"El nivel de formalización y control de nuestra sociedad es muy grande y obviamente hay transformaciones cognitivas muy fuertes, estamos ante un cambio fuerte de transformaciones en el plano perceptivo mucho más violentas, que no es equiparable al paso de la oralidad a la escritura. En cuanto a la educación aparecen diversos desafios que no sólo implican tomar y utilizar prudentemente las nuevas tecnologías sino que también implica conocer los efectos de esta globalización llevada de manera perversa que genera desempleo, cambios familiares, migraciones, una enorme brecha riqueza-pobreza que se duplicó en los últimos veinte años y el crecimiento de los sistemas de discriminación. Es muy dificil dejar de triangular educación e informática con estos temas. Todo esto va a producir resultados que todavía no conocemos bien, pero sí sabemos que esta polarización sociazl implica una relación con una educación que no es pensada para todos."...( ) Ford, A. (2001). (8)

“¿Este es el proceso educativo, creer que todo es digitalizable? Se realizaría la utopía de la homogeneidad. Lo que ocurre es que la educación está incluida dentro de la percepción global de que todo que la educación hay que manejarla. La gente empieza nlobal de que todo es información y si todo fuera un sistema de estamos hablando de estamos hablando de cómo se construye un Post grado, no en el sentido como como una profundización del conocimiento y no como una máquina preparatoria de futuros engranajes dentro del sistema educativo nacional prepacomunidades que se construyen alrededor de ideales compartidos son un elemento de resistencia. El primer interrogante generalmente olvidado un ¿para qué se quiere educar?, si esta primer pregunta encuentra respuesta vendrá otra respuesta ¿cómo educar y qué tecnologías utilizar para facilitar ese cómo? La primera pregunta es la clave y su respuesta vincula a la manera en que se concibe la sociedad y al individuo que constituye esa sociedad. El mito científico-tecnológico invierte el camino, se acepta la ciencia y la tecnología como valores en si neutros, y se declara la validez universal de su aplicación. Es preciso destacar que también es una tecnología la suma de artificios que pone en juego el instructor aunque no utilice ningún instrumento mediador"... ( ) Schmucler, H. (2001) (9).

Entel, Alicia (2001) (10) manifiesta que uno de los problemas que no viene bien encarado por la investigación en Ciencias Sociales es el de la necesaria y permanente tensión entre lo uno y lo múltiple el individu de la historia, lo macro y lo micro. Suele por épocas adver movimiento pendular que den cuenta de la totalidad de las de abarcar y encontrar categorias que den cuenta prácticas sociales y humanas y la

$$
-36-
$$

resignación a comprenderlo disociando rasgos particulares, fragmentos, nudos. El gran aporte del materialismo dialéctico ha sido definido para comprender que hasta un detalle es el producto de múltiples determinaciones, donde no está ausente el proceso de negatividad y las contradicciones Aplanado en sus aspectos sustantivos es decir, historia y dialéctica o sometido a mecanismos de reedificación, el propio método dialéctico parece, a veces fuera de la mira de las Ciencias Sociales y en la vida universitaria a veces suele ser proclamado pero no siempre utilizado. La autora retoma y trata de repensar una perspectiva que Horkheimer y Adorno denominan "antropología dialéctica" y haciendo un recorrido por autores le parece sustantiva la trilogía: historia, dialéctica, subjetividades, desde la perspectiva del materialismo dialéctico. Le parece importante tomar estas cuestiones tanto en el post grado como en el grado.

Considero que el siguiente párrafo podría estar ejemplificando la postura de Entel acerca de la trilogía cuando Casullo (11) en su exposición expresa:

"Me digo que puede que sea en la universidad nacional donde hoy se refleje de manera más inocultable la crisis intelectual y cultural de la $\mathrm{Ar}$ gentina, como estación terminal de una educación pública degradada Uno se siente entrañable parte de ese universo de aulas y fotocopiadoras que pasó a ser el concreto, último y a la vez ilusorio sitio de las ideas por ellas mismas. Sitio donde efectivamente uno ejerce eso, pero en realidad vive la penuria de ese momento de ideas compartidas que nunca llega; y la conciencia en humanidades sobre todo, de la devastación permanente de una institución que no sólo convoca a su memoria, sino que además hoy por hoy retiene mundos simbólicos desvanecidos de enorme valor. Agrupa en profesores como nunca antes una biografía intelectual y política sobreviviente de dictaduras y exilios"... ( ). "Equívocos azarosos de los procesos nacionales: esa universidad aglutinante de las diásporas, ese regreso al hogar de infinidad de historias truncas y de generaciones jóvenes en espera para reemprender las disciplinas del pensamiento, esa institución incompetente a los nuevos fines, pasó a contener una historia que en realidad "ya no tenía lugar". Sin embargo la tradición ahora como reliquia, su propio descalabro, sus crisis irresolutas, antiguos blasones protectores, la salvaron del desguace estatal, de su entrada en pista modernizante bajo lógica de la época. Terminó siendo en la Argentina de las refundaciones y los grados ceros de la historia, la perplejidad de "un presente de lo que fue ".... ( ). "No es cierto que no hay posibilidad de formas culturales e institucionales de resistencia contra el vendaval trastocador de las reformulaciones económicas y la impotencia de la política"... ( ). "Lo valio- 
so que contiene es lo indefendible frente a las coordenadas del presente: ser una escena desvitalizada pero que se resiste siempre desde una astucia docente de último momento, torpe e inadecuada, a renunciar a sus criterios casi caducos de formación supuestamente "inútil" para las exigencias más inmediatas de la patética "Argentina primer mundo"... ( ): Una institución hacia su desuso, pero que todavia retiene en dicho despropósito esa antigua intención formadora de un sujeto intelectual otro y distinto al cada vez más abreviado paso de un conocedor técnico de algo". ( )

Los textos hablan por si mismos, sólo quiero destacar que los autores vuelven a poner en un lugar de centralidad en la vida académica lo valioso de la discusión, la controversia, el disenso, la pasión, el desánimo y también las ganas ante tanta incertidumbre. Respecto al ámbito específico de Las Ciencias Sociales nos muestran que la actividad científica es una construcción dinámica donde el debate, el conflicto y la provisoriedad de los análisis son parte constitutiva de una concepción de ciencia. Al mismo tiempo estas ideas expresan una preocupación por la educación y la en señanza tratando de clarificar el lugar de las nuevas tecnologias: análisis fundamental para nuestro campo especifico de Ciencias de la Educación. Análisis que pareciera que hoy ya no tienen sentido porque se ha impuesto y aceptado este nuevo modelo tecnológico.

En esta nueva economía global el proceso de producción ha sido parcelado y fragmentado en el mundo, ya no se elaboran los productos cerca de donde van a ser consumidos y se necesita que sean elaborados de manera más eficiente y económica. Ha cambiado la concepción de organización, ésta debe ser: dinámica, con diversas líneas paralelas de poder y decisión, extendida, flexible pero sólida, siempre en evolución. La imagen de la "telaraña" simboliza esta producción transnacionalizada, que fue desplazando a la anterior concepción de organización piramidal: jerárquica, estática y sólida. Derrida en su obra "Espectros de Marx"_(1995), se refirió a este nuevo orden mundial que ha instalado una forma de hegemonía sin precedentes. La hegemonia política-económica, al igual que la dominación intelectual o discursiva, pasa por el poder tecno-mediático, poder que de manera diferenciada y contradictoria condiciona y pone en peligro toda democracia. Es un poder de múltiples "efectos espectrales": la velocidad de aparición, del simulacro, la imagen sintética o protética, el acontecimiento virtual, el cyberspace. Considera que hay tres lugares, formas y poderes de la cultura: el discurso político de la "clase política", el discurso mediático y el discurso intelectual-erudito-académico, que están soldados por los mismos aparatos, los media, y garantizan la hegemonía del impe- rialismo. Plantea que a pesar de la victoria del capitalismo liberal y su predestinada alianza con la democracia nunca ha sido tan critico, frágil y amenazado por lo que el espectro de Marx representa todavia hoy y que se intentaría conjurar de una manera jubilosa y maniaca. Al ocultar esos fracasos y esas amenazas se pretende ocultar el potencial del "espíritu" de la crítica marxista. Pero lo que sigue siendo tan irreductible a toda deconstrucción, puede ser cierta experiencia de la promesa emancipatoria, un mesianismo sin religión. Puede ser que lo que ahora sea preciso pensar y pensar de otra manera para preguntarse adonde va, sea adónde conducir el marxismo, interpretándolo, cosa que no puede suceder sin transformación; y no adónde puede el marxismo conducirnos tal como es o tal como habrá sido. La efectividad de la promesa democrática como de la promesa comunista conservará siempre dentro de sí esa esperanza mesiánica, esa relación escatológica con el por-venir de un acontecimiento; siempre en memoria de la esperanza, y ese es precisamente el lugar de la espectralidad, que dicha condición de posibilidad del acontecimiento es también su condición de imposibilidad. Se trata de pensar otra historicidad, no una nueva historia sino otra apertura de la acontecibilidad como historicidad que permite no renunciar, sino por el contrario abrir el acceso a un pensamiento afirmativo de la promesa mesiánica y emancipatoria como promesa: como promesa y no como programa o proyecto onto-teleológico o teleo-escatológico. Pues lejos de que haya que renunciar al deseo emancipatorio hay que empeñarse en él más que nunca. Esa es la condición de una repolitización, tal vez de otro concepto de lo politico.

Derrida nos brinda elementos para analizar el contexto, para hacer una lectura crítica de nuestras herencias teóricas y prácticas y centrarnos nuevamente en el análisis político e ideológico, que es hoy más preciso que nunca. Para Follari (2003) (12) en "Espectros de Marx" Derrida logra desorientar a propios y extraños, porque alude a Marx cuando todos ya lo daban por muerto y enterrado; fue sin duda un gesto político fecundo porque Fukuyama habia alardeado sobre el fin de la historia y la condición de homogeneidad universal bajo el signo del capitalismo planetarizado. Y ese gesto implicó valentía y capacidad para ponerse por encima de la inmediatez y expectativas del momento, fue una decisión política para recordarles a los dueños del capital que la historia no está clausurada. (Derrida estuvo preso en Praga por los agentes del sovietismo). Es de hacer notar que entre los derrideanos no abundan las referencias a este libro, pero en el autor no parece un oportunismo, mas bien el riesgo de quien se asoma a tierra de nadie, porque es de destacar que en los años sesenta todo intelectual progresista se definia como marxista y uno de los pocos que no 
cedió a ese facilismo fue él. Los ires y venires al azar de las modas intelectuales no se advierten en su sobriedad ideológica que sostuvo con persistencia y tampoco coqueteó con el estructuralismo cuando éste se impuso. Pero también Follari hace referencia que en los últimos tiempos se advierte una cierta forma de neofundacionalismo en la obra de Derrida inferible de algunos de sus textos cuando plantea que:

La deconstrucción puede medirse con cualesquiera otros discursos de las ciencias sociales yhumanas, estas últimas deben dar cuenta de su consistencia al ser sometidas a la deconstrucción, la cual obra como patrón de valoración externo.

No importa cuál sea el específico objeto ni la peculiar metodología de esas teorías, ellas son siempre sometibles a los criterios que la deconstrucción ha producido.

Se convierte de ese modo la deconstrucción en la medida tipo ante cualquier clase de discurso en ciencias humanas y sociales, no importando cuál sea su temática, métodos, alcances explicativos. Surgiendo así la pregunta."¿Qué justicia se hace a la deconstrucción y a su insistencia en la diferencia cuando se juzga universalmente y sin atención alguna a la especificidad de los objetos de análisis? La deconstrucción no es un criterio universal de análisis y a esta pretensión se abandona crecientemente Derrida, suponiendo que el discurso podría tener pertinencia por encima de los objetos particulares y del reconocimiento de la especificidad de las disciplinas. El sigue asumiendo que su obra juega invariablemente un papel "progresista" y de resistencia, sin referencia alguna a las especificas condiciones sociales de inscripción Para Follari la deconstrucción tenía sentido como negatividad en tiempos de fundamentos fuertes, de pretensiones de verdad asentadas, de criterios de verificabilidad "duros", del poder sostenido en el autoritarismo y el disciplinamiento, pero nada de eso subsiste como dominante en la sociedad posmoderna. Hoy la deconstrucción se ha vuelto en EE. UU., y sus departamentos de estudios literarios y culturales el espacio de la hegemonia y el campo discursivo legitimado "positivamente"; y ese discurso se ha ido convirtiendo en propuesta oficial.

Derrida ha sido un defensor de la pluralidad, considerando que todo "concepto" liquida las diferencias, la peculiaridad del mundo El concepto es una forma de generalización, de unidad tiránica, un intento de capturar la variabilidad de la realidad. Por eso plantea la deconstrucción, desarmar la unidad del concepto, la unidad de sentido. Pertenece al: Postestructuralismo: movimiento de finales de 1970, corriente que plantea que el sujeto es portador de estructuras (lenguaje), dándole preeminencia al lenguaje, a las diferencias, a lo micro, al acontecimiento, a la peculiaridad de lo que acaece, superando el encuadre de la razón, tratando de captar lo que ocurre como algo inesperado, no reducible a conceptos. Lo. postmoderno es una condición de época que ha clausurado el tiempo de vigencia del postestructuralismo y la deconstrucción. Sus exponentes son: Lyotard, Braudillard, Vattimo, Lipovestky). Lo posmoderno se destaca por su explícito conformismo y donde se asume lo real como simple "situación dada". Follari (2000) propone asumir lo posmoderno como un "factum" innegable, pero dentro de su formato reinscribir ciertas temáticas de la modernidad como es la criticidad sobre lo político-global porque considera que un proyecto social alternativo de ningún modo basta con que implique una simple reinvidicación de la diferencia.

La postmodernidad es definida por Gruner, E. (2002) como la actual fase de desarrollo globalizado del mundo capitalista. Capitalismo tardío, como una nueva fase de acumulación del capital con su nueva forma de racionalidad: descentralización y segmentación productiva, distributiva, financiera y comercial "posfordista". La diferencia es que el capitalismo sí ha logrado su unificación global a través de sus sectores financiero, de servicios, informático, comunicacional transnacionalizados. Un capitalismo sin base material en el sentido clásico ya que su soporte principal son los signos. La "transparencia" es el gran mito de nuestro tiempo: todo se hace visible y comunicable; de alli el cuestionamiento postmoderno al concepto mismo de "representación". Este capitalismo semiotizado ha producido todo tipo de cambios: en las relaciones sociales, en la organización del trabajo, en la cultura; ha producido nuevas "subclases", "nuevas identidades" y nuevas formas de "ciudadania". Al mismo tiempo ha contribuido a homogeneizar y unificar extraordinariamente el poder y su concentración sirviendo lo múltiple para escamotear lo Uno. Considera que ante esta redefinición del espacio productivo y perceptivo de la totalidad-modo de producción no se diluye la pertinencia del marxismo.

Esta nueva fase de desarrollo globalizado he tratado de conceptualizarla a través de los distintos autores mencionados, con sus enfoques particularizados que nos permiten complejizar la mirada acerca de los cambios socio-económicos que se fueron gestando a lo largo de estos años y también buscar en las argumentaciones de los autores los acuerdos y los disensos como en el caso de Follari acerca de Derrida.

Asumiendo algún beneficio de la globalización: tener información actualizada al instante acerca de lo que acontece en otro lugar del planeta, accedi a un artículo periodistico sobre la temática aquí desarrollada. Múltiples ventajas que nos brinda la era informática pero si también tenemos 
presente esas preguntas sustantivas: ¿que hacemos con la información? ¿para qué seleccionamos esa información? Utilizando entonces esa ventaja de tener un rápido y fácil acceso a las noticias del mundo, tomo en consideración un artículo periodístico cuyo titular es: "Universidades en crisis", que analiza la realidad actual de las universidades de E.E.U.U. de Europa y de Argentina. (13)

Durante la mayor parte de su historia el sistema universitario de E.E.U.U. respondió a la misión de progreso económico y social, pero esta función de integración social fue siendo gradualmente abandonada. El único criterio que prevalece es una temible clasificación entre "buenas" y "malas" universidades. Más que garantizar la calidad global de la enseñanza el sistema de selección legitima la importancia de los medios económicos otorgados a los establecimientos de elite, que representan apenas el 10 $2 \%$ del conjunto. Por ej.: la universidad californiana de Stanford que ya dispone de un fondo patrimonial de 14.000 millones de dólares lanzó recientemente una campaña para recolectar 4300 millones suplementarios. La selección que se realiza permite asegurar a una pequeña elite recursos casi ilimitados. Esta situación contrasta con la de los años de prosperidad que siguieron a la $2^{\circ}$ guerra mundial. En esos tiempos el gobierno confiaba a la universidad pública la misión de reducir las desigualdades: a partir de 1945 E.E.U.U. construyó numerosos establecimientos públicos destinados a aumentar masivamente el acceso de las clases populares a un diploma de educación superior, convirtiéndose en un crisol de cohesión social. Entre 1940 y 1970 la cantidad de estudiantes pasó de 1,5 a 8 millones y durante los treinta años siguientes esa cifra se duplicó. Paradójicamente ese paréntesis igualitario se debió en buena parte a la Guerra Fría, en un clima político anticomunista y antisocialista, convirtiéndose la universidad en el instrumento ideal que permitía disfrazar de meritocracia a la estructura social del pais, (se utilizó la amenaza militar soviética para el pago de onerosos créditos a la investigación). La universidad encarnaba la fusión entre enseñanza e investigación; los investigadores empezaron a percibirse como una de las fuerzas vivas de la economía post industrial y los estudiantes se mostraban más abiertos a los movimientos sociales en la medida en que en sus campus toleraban e incluso alentaban la igualdad entre los sexos y las razas. La universidad parecía operar la síntesis entre servicio público y excelencia, igualitarismo y riqueza y se consideraba a sí misma el reflejo de una democracia cada vez más multirracial que aspiraba a expandir las fronteras del conocimiento. La guerra cultural que desplegó la derecha para destruir esos logros apuntó en $1^{\circ}$ lugar contra las universidades estatales de gran tradición social y buscó mermar el poder de la "nue- va clase" y apuntaron a un aislamiento científico por no responder lo suficiente a la lógica del mercado. El sistema fiscal y las privatizaciones fueron los brazos armados del conflicto que desembocaron en una disminución de los fondos destinados al sistema de educación pública reduciendo los presupuestos de las universidades del Estado. Para subsanar esa falta recurrieron al mecenazgo, sobre todo para financiar investigaciones especificas y aumentaron el costo de la matrícula. Al mismo tiempo el fondo patrimonial de las universides privadas favorecidas por la generosidad de los donantes cada vez más ricos sube entre un 10 y un $20 \%$ anual hace 15 años.

El contraste entre la riqueza de las universidades privadas y los problemas de los establecimientos públicos condujo a éstos últimos a entrar en la misma lógica. El aumento de las matrículas apareció como el único recurso posible y duplicaron su costo desde 2001. Al rivalizar para atraer a los alumnos más solventes lo único que logran es acentuar la fractura social, dado que los estudiantes pobres se encuentran casi siempre en los establecimientos más desprovistos, al mismo tiempo que su deuda y la de sus padres aumenta. En este contexto de cambio a partir de los años 80 las nociones de apertura al gran público y la de "calidad" se perciben como antinómicas. Hoy la enseñanza de calidad está reservada a los más ricos, hay una marcada estratificación social. Newfield, C. (2007). (14).

El autor propone reinventar una visión igualitaria de la utilización de los saberes, pero considera que lo más probable es que sea el conjunto de los estadounidenses y no la universidad misma quien imponga una decisión de ese tipo.

¿Qué ocurre en Europa? Desde la armonización europea que siguió a la Declaración de Bolonia en 1999 (objetivo: la convergencia de los sistemas de enseñanza superior en Europa) el discurso y las miras de la politica universitaria sufrieron una mutación completa. Los objetivos humanistas y culturales fueron sustituidos por una competencia calcada del mundo de la empresa y de los intercambios comerciales. En la actualidad las universidades son comparables a firmas o marcas que se dividen un mercado de profesionales cuyo valor social se mide en función de la salida laboral y de los salarios que obtienen los premiados con esa "inversión educativa". Se manejan ciertos indicadores que posibilitan estar en el ranking internacional, entonces las universidades orientan su politica de manera de mejorar el "puntaje". Se ha instalado una lógica contable que influye sobre la gestión del personal, la politica de las matriculas, las creaciones o supresiones de materias, la política de evaluación de los docentes e investigadores, el llamado a asociarse con el sector privado o los mecenas. Según 
el informe 2005 de la OCDE los establecimientos italianos llegaron al $3^{\circ}$ puesto en la tasa de autofinanciamiento. La ley francesa de julio 2007 , sobre autonomia de las universidades, transforma al presidente en un gerente asistido por un consejo de administración que él controla por completo. Plantea Charle, C (2007) (15) que el darwinismo educativo está delineado y que el tráfico financiero amenaza con reemplazar al de las ideas. Se matarán dos pájaros de un tiro: se suprimirá uno de los últimos espacios críticos del orden establecido y se legitimarán las fracturas sociales cada vez más grandes

¿Cuál es la situación en Argentina? En ese contexto internacional las universidades públicas argentinas capearon airosamente el temporal de las tendencias privatizadoras y empresariales de los 90 . Pero se necesita volver a pensar el sentido, la misión de la universidad para volver a su naturaleza particular, como una institución del conocimiento y no como una fábrica de diplomas devaluados. Habrá que refundarla para fortalecer las políticas del conocimiento al servicio de un proyecto emancipador, local y con capacidad de resolver las urgencias que genera la brecha entre los paises independientes ricos y los países dependientes pobres. Mollis, M (2007) (16).

Estos análisis, que requerirán su profundización, nos muestran que este modelo va afectando a todos, también a paises del primer mundo, probablemente con diferencias, pero desde la misma concepción de "modernización a través del ajuste". Ante este panorama de consolidación del modelo parecieran obturadas las posibilidades de pensar y hacer algo diferente.

En lo institucional especifico estoy convencida que la tarea nos corresponde a todos, autoridades, docentes, alumnos, graduados y el resto de la comunidad universitaria. Podriamos volver a pensar en aquella premisa: Los docentes pretendemos lo "mejor" de los alumnos y los alumnos pretenden lo "mejor" de los docentes. Seria un eje básico para una educación de calidad, con compromisos mutuos. Calidad para pensarla entre nosotros, con otros, entre todos, desde las posibilidades reales pero también con utopias. Y creo que el eslabón imprescindible son los graduados porque brindarian la posibilidad de analizar la formación que tuvieron y su inserción laboral, aunque no tendría que ser solamente ese el eje de análisis porque podría ser una mirada muy pragmática. También seria interesante incorporar como corpus de teoría y acción las dificultades que tuvieron en la enseñanza, qué propuestas hicieron a nivel áulico o institucional, y también social, qué experiencias de lucha y resistencia tuvieron en sus instituciones.
Miradas micro relacionadas con miradas macro, en una relación dialéctica, para poder generar respuestas que aporten a la transformación social más allá de las paredes de la Universidad. Ese ha sido el objetivo de este trabajo buscando en tres documentos los significados de actores cercanos y entrelazarlos con otros más lejanos pero muy cercanos.

Comparto la afirmación del profesor Follari, R (2006) (17) cuando expresa que: El conocimiento no es el nuevo capital, sino que ahora cumple una nueva función decisiva en cuanto a la acumulación del capital, lo cua es muy diferente. En un mundo donde la competitividad está centrada en el cambio tecnológico y el valor agregado de un producto por la intervención tecnológica es fundamental para establecer su precio de mercado, el saber que informa tales condiciones tecnológicas alcanza una importancia estratégica. El conocimiento no es el nuevo capital económico sino que colabora a generarlo, pero no cualquier conocimiento es valorizado por el capital, sólo aquel con consecuencias tecnológicas determinables. No hay por tanto una sociedad del conocimiento, lo que hay es un capitalismo que hace de él una fuente permanente de ganancias y valorización sólo de aquél que sea tecnológicamente asimilable; reduciendo la abstracción conceptual del conocimiento teórico científico a lo operativo y reduciendo to explicativo a lo aplicativo. Dentro de una sociedad pragmatista se erosiona la legitimidad de las instituciones de educación superior; la cultura posmoderna liquida la fundamentación y los intelectuales son reemplazados por los formadores de opinión mediáticos. Asistimos a un debilitamiento de las condiciones de exigencia epistemológica para la actividad científica, al considerarse a la ciencia como un sistema de creencias equivalente a cualquier otro (línea que abrió Feyerabend). Podría pensarse en una radical democratización del conocimiento pero también en su total indiferenciación respecto de cualquier modalidad de opinión, lo cual hace prescindible su financiamiento é institucionalización. Todo ello colabora al gradual descrédito de la universidad, en un proceso de deslegitimación en crecimiento, ligado a la falta de pertinencia social que se adscribiría a la institución universitaria. Este pragmatismo de fuerte pathos anti teórico ha llegado a la universidad y se está aniquilando la ciencia básica. De esto derivan planes de estudio que adecuan punto a punto la oferta educativa a los perfiles exigidos desde los puestos de trabajo presentados por los empresarios. La Universidad no puede alienarse totalmente de sí misma y no puede ser sólo un espacio de respuestas a las demandas externas. El rol del conocimiento no es solamente satisfacer lo que se le propone desde la sociedad sino también reelaborarlo y esclarecerlo; la demanda pragmática debe ser decodificada. 
Creo que es importante que sigamos sosteniendo como válidos los pilares que brindan los distintos fundamentos teóricos en una Carrera de Ciencias de la Educación, y rescatemos las actitudes que en el texto se señalan como relevantes: polemizar, discutir, argumentar, anticiparse, abrir interrogantes, para generar propuestas transformadoras a la comunidad educativa y a la sociedad. $Y$ después de haber pensado el por qué y para qué, que implica toda selección de conocimientos pensemos la otra pregunta que también nos compete como docentes ¿Cómo? ¿Con qué tecnologias? para optimizar nuestros andamiajes y posibilitar el aprendizaje de nuestros alumnos.///

\section{Notas Bibliográficas:}

(1) Documento: "El pais, la universidad y la crisis", 1989 fue escrito por docentes y algunos alumnos de la Facultad de Humanidades y Artes. U.N.R. Fueron convocados por el ex decano $F$. Prieto, para pensar y analizar ese momento histórico por sus implicancias para la Universidad Argentina y nuestra Facultad en particular. Este trabajo toma en consideración las ideas de los distintos autores, pero fundamentalmente el análisis que realizan las profesoras: Bonaudo, M. y Sonzogni, E. en: "La Universidad democrática: Un balance crítico de su funcionamiento."(pág. 11-15).

(2) Carretero,M.,Rosa,A. González,María (2006)" Enseñar historia en tiempos de memoria",Introducciónen.:Carretero,M.,Rosa,AGonzález,Maria(Comp.):Enseñanza de la Historia y memoria colectiva. Buenos Aires. Paidos. Se destaca que la edición de este libro ha contado con el apoyo del Programa Alfa (Unión Europea).

(3) Las ponencias en ese Simposio Internacional son editadas en el texto "Curriculum Universitario Siglo XXI" (1994) en Cuadernos 2, Publicación, de la Facultad Ciencias Educación. U.N.E.R. Esta publicación sólo se refiere a algunas ponencias, entre ellas figuran las del Prof. Follari, R. y Torres, C. que se analizan en este Articulo.

(4) Follari, R. (1994). "Los retos del Siglo XXI ante el estado evaluador", en Torres, C Follari, R; Albornoz; M, Duluc, S; Petrucci,L.: Curriculum Universitario Siglo XX.I. (Cuad. 2). Entre Ríos. Cepce.U.N.E.R.

(5) Torres, C (1994)."La educación superior en América Latina: de la Reforma de 1918 al ajuste estructural de los noventa", en Torres, C; Follari, R; Albornoz;M, Duluc,S; Petrucci,L.: Curriculum Universitario Siglo XXI. Cuad.2. Entre Rios. Cepce. U.N.E.R.

(6) Stuart Hall (1993)." Nuevos Tiempos." "The meaning of new times" (trad.Delfino S. Cap.2.2.3. en Delfino, S. La Mirada Oblicua. Buenos Aires. La Marea. Fue director del Centro de Estudios Culturales Contemporáneos de la Universidad de Birmingham, Inglaterra,(entre 1964 y 1969). Sus análisis de prácticas e instituciones en relación con el cambio social incluyeron formas simbólicas y rituales de la vida cotidiana.
(7) Casullo, N. (2001) (a). "Entre pensamiento y academia: los bordes del abismo", en Rosa, N. (director) Ciencias Sociales y Postgrado. Papeles de Investigación I. Año I. No1. U.N.R. Rosario. Laborde Editor, pp.40-46.

(8) Ford, A (2001). "Sociedad y educación en la desigualdad infocomunicacional", en Rosa, N. (director) Ciencias Sociales y Postgrado. Papeles de Investigación I. Año I. No1. U.N.R. Rosario. Laborde Editor, pp.58-64.

(9) Schmucler, H. (2001)"El analfabetismo informático", en Rosa, N. (director) Ciencias Sociales y Postgrado. Papeles de Investigación I. Año I. No1. U.N.R. Rosario. Laborde Editor, pp.147-157.

(10) Entel, A. (2001). "Notas para una antropología dialéctica", en Rosa, N. (director) Ciencias Sociales y Postgrado. Papeles de Investigación I. Año I. No1. U.N.R. Rosario. Laborde Editor, pp.33-39

(11) Casullo N. (2001).(b) "Notas a pie de página de un siglo”, en Rosa, N. (director) Ciencias Sociales y Postgrado. Papeles de Investigación I. Año I. No1. U.N.R. Rosario. Laborde Editor, pp.128-132.

(12) Follari, R. (2003). Teorías Débiles. (Para una crítica de la deconstrucción y de los estudios culturales. Rosario. Homo Sapiens. pag.39-49. El autor aclara en op.cit. pág. 55 que: Estudios sobre cultura no significa técnicamente lo mismo que "estudios culturales" que es una categoria determinada.

(13) "Universidades en crisis"(2007, set) en periódico "Le monde diplomatique", "el Dipló"(español).

(14) Newfield, C. (2007) "Del igualitarismo a la fractura social". En Estados Unidos: la regresión, en periódico "Le monde diplomatique","elDipló"(español)

(15) Charle, C. (2007) "Empresas académicas". En Europa: estar en el ranking, en periódico "Le monde diplomatique","el Dipló"(español)

(16) Mollis, M. (2007) "Refundar la U.B.A". En Argentina: crisis de sentido, en el periódico "Le monde diplomatique","elDipló" (español).

(17) Follari, R._(2006). "Cuestionamientos actuales sobre contenidos científicos, saber Profesional y organización curricular", en Congreso: Los saberes del docente universitario, en Univ.Nac. Mejico. D.F. Conferencia.

\section{Referencias Bibliográficas:}

- Apple, M. (1996). El conocimiento oficial. Barcelona, Paidos.

- Carretero M., Rosa, A. y González M. (2006). Enseñanza de la Historia y memoria colectiva. Buenos Aires. Paidos.

- Derrida, J. (1995). Espectros de Marx. Madrid. Edit.Trotta.

- De Sousa Santos, B. (1999). Pela Mao de Alice. Lisboa. Edit.Afrontamento

- Dussel, I y Finocchio, S. (compiladoras). (2003). Buenos Aires. Fondo de Cultura Económica de Argentina. S.A.

- Follari, R. (1994). "Los retos del Siglo XXI ante el estado evaluador", en Torres,C ;Follari,R; Albornoz; M, Duluc,S; Petrucci,L.: Curriculum Universitario Siglo XX.I. (Cuad. 2). Entre Rios. Cepce.U.N.E.R.

- Follari, R. (2000). Epistemología y Sociedad. Rosario. Edit. Homo Sapiens.

- Follari, R. (2003). Teorias Débiles. Rosario. Homo Sapiens. 
- Follari, R._(2006). "Cuestionamientos actuales sobre contenidos científicos, saber Profesional y organización curricular", en Congreso: Los saberes del docente universitario, en Univ.Nac. Mejico. D.F. Conferencia.

- Gibbons, M (1997). La nueva producción del conocimiento. Barcelona. Edic.Pomares, Corredor S.A.

- Gruner, E. (2002).El fin de las pequeñas historias.. Bs.As. Edit. Paidos

- Giroux, H. (1997). Cruzando limites. Barcelona. Paidos

- Imbernón, F. (Coord.) (1999). La educación en el siglo XXI. Barcelona. Biblioteca de Aula.

- Marcuse, H. (1968)_El hombre unidimensional. Mejjico. Joaquín Mortiz.

- Rosa, N. 2001). (Director). Ciencias Sociales y Postgrado. Papeles de Investigación I. Año I. No1.U.N.R. Rosario. Laborde Editor.

- Stuart Hall, A. (1993)." Nuevos Tiempos." "The meaning of new times" (trad.Delfino S. Cap.2.2.3. en Delfino, S. La Mirada Oblicua. Buenos Aires. La Marea

- Torres, C (1994)."La educación superior en América Latina: de la Reforma de 1918 al ajuste estructural de los noventa", en Torres, C; Follari, R; Albornoz, M Duluc, S; Petrucci,L,: Curriculum Universitario Siglo XXI. Cuad.2. Entre Rios. Cepce. U.N.E.R.

\section{LOS PROCESOS DE ACREDITACIÓN DE POSGRADO DE LA UNIVERSIDAD NACIONAL DE ROSARIO EN EL PERIOODO} 1995-2005.

Prof. Lic. Rosanna Schanzer (Universidad Nacional de Rosario)

Prof. María Cecilia Muruaga (Universidad Nacional de Rosario)

\section{Resumen}

La acreditación constituye un tema de actualidad para la investigación sobre Educación Superior Universitaria y se vincula a aspectos diversos: calidad de los mecanismos empleados, posibilidades para su implementación en el marco de la autonomía universitaria, trasnacionalización de las acreditaciones orientadas a los acuerdos regionales, tensiones que atraviesan los procesos. El presente trabajo presenta un primer acercamiento a los resultados de un proyecto de investigación que se propone evaluar los procesos de acreditación de posgrado en el ámbito de la Universidad Nacional de Rosario durante la década 1995-2005. A tal fin se consideran los procedimientos de acreditación desde las percepciones de la comunidad académica implicada en ellos.

\section{Palabras clave:}

Acreditación, Posgrado, Evaluación, Educación Superior Universitaria, Actores institucionales

\section{Summary}

Accreditation constitutes a subject of the present time for the investigation on Higher Education and it ties to diverse aspects: quality of the used mechanisms, possibilities for its implementation within the framework of the university autonomy, trasnacionalization of the accreditations oriented to the regional agreements, tensions that cross the processes. The present work presents a first approach to the results of an investigation project that sets out to evaluate the processes of posgrado accreditation in the scope of the National University of Rosary during decade 1995 - 2005. To such aim the accreditation procedures are considered from the perceptions of the implied academic community in them. 